\title{
Carbon footprint of textile throughout its life cycle: a case study of Chinese cotton shirts
}

\author{
Chenxing Wang ${ }^{\mathrm{a}, \mathrm{b}}$, Lihua Wang ${ }^{\mathrm{c}}$, Xinlei Liu ${ }^{\mathrm{c}}$, Chong Du ${ }^{\mathrm{c}}$, Ding Ding ${ }^{\mathrm{d}}$, Jia Jia ${ }^{\mathrm{e}}$, \\ Yan Yan ${ }^{\text {a, }}$, Gang $\mathrm{Wu}^{\mathrm{a}}$ \\ a State Key Laboratory of Urban and Regional Ecology, Research Center for Eco-Environmental Sciences, Chinese Academy of Sciences, \\ Beijing 100085, PR China \\ ${ }^{\mathrm{b}}$ University of Chinese Academy of Sciences, Beijing 100049, PR China \\ c China Certification \& Inspection Group Testing Technology Co., Ltd., Beijing 100028, PR China \\ ${ }^{\mathrm{d}}$ National Center for Climate Change Strategy and International Cooperation, Beijing 100038, PR China \\ e CPI Science and Technology Research Institute, Beijing 100011, China
}

\section{A R T I C L E I N F O}

\section{Article history:}

Received 28 September 2014

Received in revised form

26 May 2015

Accepted 31 May 2015

Available online 9 June 2015

\section{Keywords:}

Carbon footprint

Textiles

Life cycle

Cotton shirts

China

\begin{abstract}
A B S T R A C T
The carbon footprint (CFP) reflects the greenhouse gases (GHGs) generated throughout the life cycle of a human activity or product, and is therefore an important tool for assessing and managing GHG emissions. At the level of an individual product, a carbon-labeling scheme that provides more information for consumers could play an important role in encouraging a shift to low-carbon consumption. China is the largest textile and garment producer and consumer in the world. Studying the carbon footprint of textiles is therefore important domestically, for the management of domestic greenhouse gas emission and, internationally, for the communication of carbon information and relevant trade negotiations. For establishing the product carbon labeling system in China, this paper constructed an operable and comparable CFP assessment method and framework at product level and presents a complete case for pure cotton shirts made in China. Based on investigations of several Chinese textile companies and the observation of every production sub-process, the system boundary and methods of assessing textile product CFP were established. We then estimated Chinese CFP conversion factors for relevant energy sources and materials, and calculated the actual CFP for the life cycle of a pure cotton shirt. The average CFP of a pure cotton shirt produced in China, throughout its life cycle, is estimated as $8.771 \mathrm{kgCO}_{2} \mathrm{e}$. Of this, direct CFP is $0.347 \mathrm{kgCO}_{2} \mathrm{e}$, whereas indirect CFP is much higher, at $8.423 \mathrm{kgCO}_{2} \mathrm{e}$. The industrial production stage accounts for the highest proportion of the CFP, and overall production (including agricultural and industrial production) accounts for more than $90 \%$ of the total CFP. Approximately $96 \%$ of CFP throughout the product life cycle is indirect CFP, which is embedded in the use of energy and materials in each process. Within the industrial production stage, the transportation and weaving subprocesses account for nearly all the direct CFP $\left(0.347 \mathrm{kgCO}_{2} \mathrm{e}\right)$. Energy consumption, especially of electricity, is the main contributor to the CFP of textile products. These results could facilitate comparison between different products, and for the same products from different producers, In order to reduce the CFP throughout the entire textiles sector.
\end{abstract}

(C) 2015 Elsevier Ltd. All rights reserved.

\section{Introduction}

Global warming represents a threat to the natural environment and human economic development. Many studies have shown that global warming primarily results from the increasing emission of

\footnotetext{
* Corresponding author.

E-mail addresses: star881003@126.com (C. Wang), yyan@rcees.ac.cn (Y. Yan).
}

greenhouse gases (GHGs) as a result of human activities (Brito de Figueirêdo et al., 2013; Heijungs et al., 2010; Jamali-Zghal et al., 2013; Zhao et al., 2012). The carbon footprint (CFP) assessment is an important approach for the control and management of GHG emissions. CFP is based on the life cycle concept, and is used to assess the GHGs generated during the production of goods or services, either throughout their entire life cycle or within specified temporal or spatial boundaries (Brito de Figueirêdo et al., 2013; Dias and Arroja, 2012; Dormer et al., 2013). Carbon labeling 
application systems at product level can provide consumers with information on the carbon emissions associated with every process throughout the product life cycle. By providing quantitative CFP labels for each process involved in the manufacture of a product, carbon labeling application systems can help improve social lowcarbon consciousness and promote enterprises that carry out emission reduction activities. The unified and comparable product CFP assessment with the associated framework, methods, and foundation database is the basic premise for effectively applying the carbon labeling application system.

Textiles are important consumption goods and international trade products. Chinese textile companies collectively produced nearly $30 \%$ of the textile products for the global market in 2010. The scale of domestic textile consumption within China is also very large (Muthu et al., 2012). The CFP assessment of textiles helps to understand the basic conditions associated with the emission of GHGs during their production and consumption. This not only helps to analyze GHGs emitted during specific processes of the life cycle (Chen and Wang, 2006, 2009; Tang and Wan, 2003), but also plays an important role in communicating information about the environmental performance of Chinese goods and manufacturing, which is important to textile carbon labeling and international trade (Sun et al., 2011; Wang et al., 2012; Huang et al., 2011).

The application and promotion of carbon labeling require data, assessment methods, and CFP framework at product level, which are more specific, impartial, and comparable (Dai et al., 2011). The general understanding of the concept of product CFP is to estimate the total GHGs emitted over the full life cycle or individual processes (Herva et al., 2012; Wiedmann and Minx, 2008). CFP assessment is mainly based on international standards and regulations, such as PAS 2050 published by the Carbon Trust, BSI, and Defra; ISO 14067 published by the International Standardization Organization (ISO); etc. As the first standard for CFP assessment, PAS 2050 focused on GHG emissions during the product life cycle. However, the assessment methods and concepts of the Carbon Trust used to perform CFP assessment and calculations can be affected by differences in production data and are difficult to compare with other similar products (BSI et al., 2011). The ISO 14067 standard contains two parts that are ISO 14067-1 Quantification and ISO 14067-2 Communication. ISO 14067 provided the general CFP assessment framework of products with universality. However, for specific product CFP assessment, relevant data collection, system boundary definition, and CFP conversion factors still need more research and studies on their practical application (Standardization, 2013).

With the development of these organizations and standards, there have been lots of CFP assessment cases at product level faced to the application of carbon labeling system. However, bound by different system boundaries and the limitation of data collection, previous CFP assessments at the product level were mainly based on the top-down methodology and established through statistics and macro data distribution in the entire organization, which have difficulty to compare among different assessments due to the difference of system boundary and difficulty to disassemble and reassemble. Therefore, the CFP assessments at the product level needs more precise assessment method and data system for comparing with different manufacturer, different technique. The bottom-up assessment methodology which uses direct data from detailed process in life cycle and has clarifying the specific system boundary. Result of CFP by such methodology can be disassembled and reassembled, which make it possible to compare the results from different assessments of similar products. However, so far, there are several obstacles to application of the bottom-up assessment methodology, such as difficulty to trace and monitor detailed processes of production, lack of primary data and so on, that's why there are few CFP assessment cases by such methodology till now. This paper proposed a comparable CFP assessment framework, calculation systems, and basic databases for textile products with the aim of applying product carbon labeling. We constructed a more comparable and operable product CFP assessment method and data system that is based on the bottom-up assessment methodology, and present case study of the textile products in China. Based on detailed data collection, we conducted a complete case study to testify and demonstrate this method, and we hope it would be meaningful and helpful to relevant researchers.

In this research, we constructed comparable CFP assessment methods, frameworks, and standards for general textiles and collected production data by investigating numerous textile enterprises in China, including the individual industrial production processes and CFP conversion factors of basic energy resources. We hope to provide a comparable bottom-up CFP assessment method and basic database for the carbon labeling application system of Chinese textiles. This paper focused on pure cotton shirts made in China, investigating the complete life cycle in order to demonstrate the applicability of the CFP assessment methods, framework, and basic database. Calculation data were from investigation of several Chinese textile companies, observations of every production process, and some statistical data. What's more, to reflect the difference of energy resources in China, CFP conversion factors for energy resources were estimated by calculation of the CFP in each process of production, transportation, transformation (Pennington et al., 2004; Rebitzer et al., 2004). The results provide general indications of the CFP scenario for Chinese cotton shirts on some extent, and provide a specific example and reference for relevant researchers, managers, and stakeholders.

\section{Material and methods}

There are two basic CFP assessment methodologies for product CFP assessment, top-down and bottom-up. Combined with input-output analysis, the top-down CFP assessment measures and analyzes the GHG distribution process and flow direction of departments and products. The bottom-up CFP assessment is based on process analysis and focuses on the GHG emissions of each process. Therefore, the bottom-up CFP assessment provides the CFP of each process in the product life cycle. It also has further advantages in terms of being able to compare and reflect the variance in processes and impact factors.

\subsection{Case study and functional unit}

The study case consists of a pure cotton shirt that is produced entirely in China. In terms of the main production sub-processes-spinning, weaving, and clothing - we investigated several large-scale textile enterprises during 2009-2010, during which we observed the usage of every form of energy, material, equipment, and so on.

In the present study, a pure cotton shirt of average weight $0.28 \mathrm{~kg}$ is used as the functional unit when observing the industrial production and in investigating the other main life cycle process, such as sourcing raw materials, transportation and distribution, product usage and disposal. In the actual calculation, we need to consider the quality loss in production and other processes, such as the normal material loss and the loss by quality.

\subsection{Assessment framework and system boundary}

The assessment framework is an important and deterministic part of product CFP assessment. The methods presented in the IPCC 
report (Change, 2006), ISO 14067, and PAS 2050 (Specification, 2011) all offer general assessment principles and a system framework (Finnveden et al., 2009; Li, 2009). The system boundary for assessment of the shirt CFP in the present study (see Fig. 1) is based on these principles especially the IPCC methods, and on the investigation of the main life cycle processes and a summary of all of inputs/outputs. The CFP assessment in this paper involves calculating not only the direct and observable emission of GHGs, but also includes estimates of the indirect emissions that are embedded within the product life cycle.

The life cycle of cotton shirt is comprised of cotton production, transportation of cotton, industrial production, transportation of shirts, usage process and disposal process. The system boundary of our assessment includes all of processes in the cotton shirt life cycle except disposal process. The CFP of cotton production includes GHGs related to the physiological action in cotton growth (e.g. photosynthesis and respiration), and cultivation management (e.g. fertilizers and pesticides, energy consumption). The industrial production process includes production, management and other parts sub-processes. In the transportation process we mainly calculate the CFP of the energy consumption for transportation vehicles usage, but the production and disposal of these vehicles are not included.

When delimiting the system boundary of CFP assessment, based on the demand of the application of carbon labeling system, the system boundary just needs to include the processes from cradle to gate. However, the usage process makes obvious contributions to the GHGs emission of a cotton shirt in the whole life cycle, so the system boundary in this paper was extended to the usage process. However, the disposal process is not included in the actual assessment system boundary in this paper, because according to our investigation, contribution to GHGs emission of the disposal process is inapparent that there are only small proportion of cotton shirts put into concentrated disposal process which may make contribution to the direct GHGs emission such as waste incineration or landfill, but most others are recycling and reusing by families or by manufactories which do not make obvious contribution to the GHGs emission. And, it is really quite difficult to do the relevant investigation and get accurate data of this process.

The main relevant input factors for CFP calculation in this paper are energy resources consumption like coal, oil, gas, steam and electricity, and materials consumption such as dyes, bleach, solvents and so on. The system boundary also includes the processes of mining, transforming, and transportation within the life cycle of these energy sources and the processes of production and transportation for materials. The assessment result includes the direct GHG emissions-mainly comprising combustion for energy and the production of material inputs-and the indirect emission of GHGs during the various processes, including the sub-processes.

The textile CFP is decided to the direct and the indirect. The direct CFP is defined as the amount of GHGs emitted during the textile product's life cycle, such as GHGs from the burning of fossil energy, those released from biochemical reactions during the agricultural and industrial processes, and from direct effusion. We did not calculate the GHGs derived from human respiration, which are involved in textile production. The indirect CFP is the sum of indirect or embedded GHGs emitted by all emission sources during the life cycle of the textile product. In other words, the indirect CFP represent the GHGs attributed to energy sources and material inputs, which are emitted during their own production or transportation sub processes. These represent the additional components of the carbon footprint that are embedded within every input.

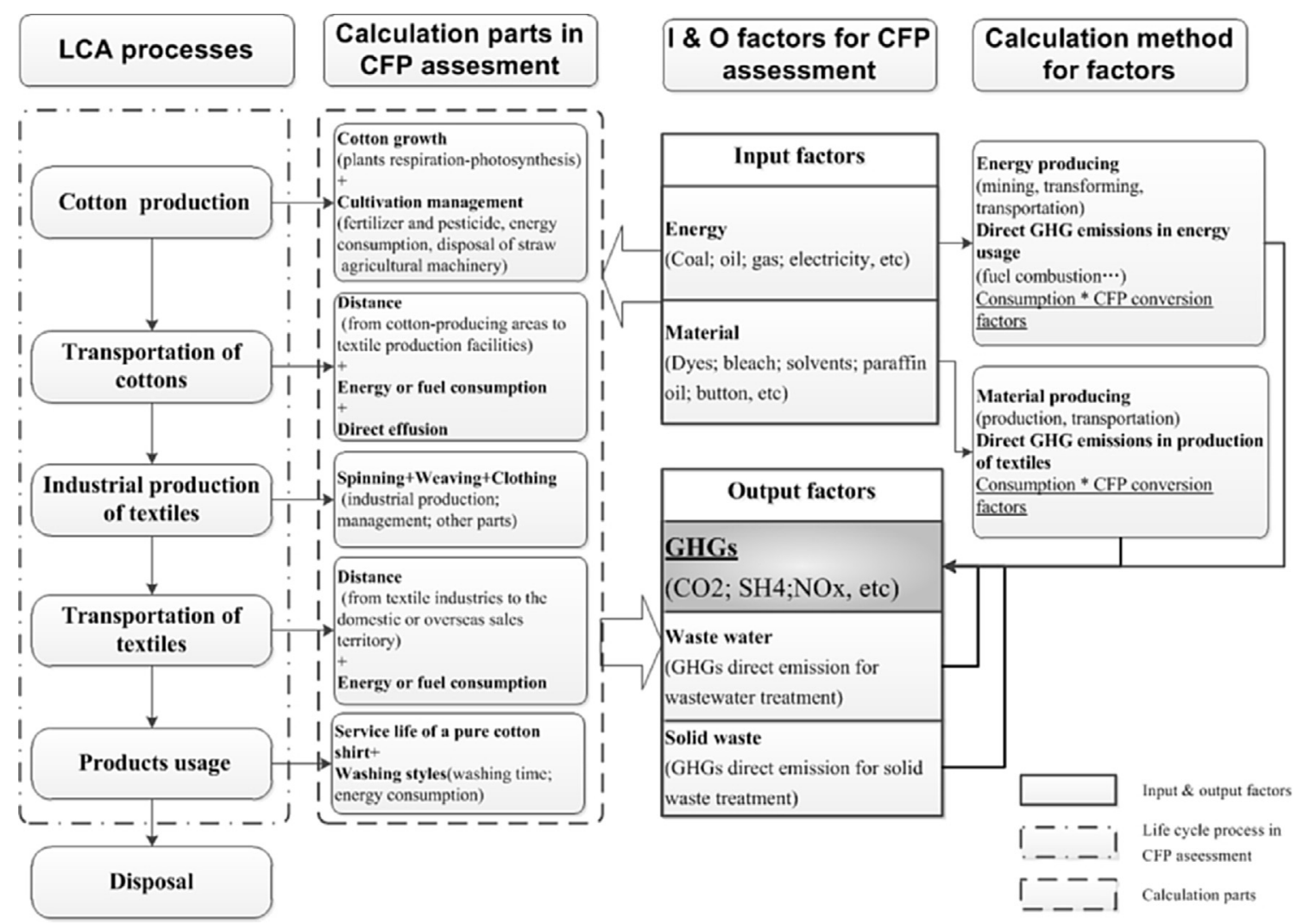

Fig. 1. CFP assessment framework of textile products. 


\subsection{Model used to calculate CFP of textiles}

The textile product bottom-up CFP assessment sums up the CFP of each process including cotton growth, cotton transportation, textile production, shirt transportation, and product usage according to the IPCC reports. The CFP of each process incorporates the direct and indirect GHG emissions of every step in this process. The GHG emissions of each step are calculated from the input of energy and materials and the direct emission of GHGs like $\mathrm{CO}_{2}, \mathrm{CH}_{4}$, $\mathrm{NO}_{\mathrm{X}}$, etc.

The specific assessment model of product CFP by one function unit $(0.28 \mathrm{~kg})$ is estimated as shown in Eq. (1):

$$
\begin{aligned}
C F= & \sum_{n} C F_{n} \\
= & \sum_{n}\left[\left(\sum_{i} E_{i n} \cdot \omega_{i}^{d r}+\sum_{i} E_{i n} \cdot \omega_{i}^{i n}+\sum_{i} M_{i n} \cdot \xi_{i}^{d r}+\sum_{i} M_{i n} \cdot \xi_{i}^{i n}\right.\right. \\
& \left.\left.+\sum_{i} C h_{i n}\right) /\left(1-M_{n}^{\text {Loss }}\right)\right]
\end{aligned}
$$

Here, $n$ is the number of CFP assessment sub-processes that could not be divided in the life cycle of textile products, $C F_{n}$ is the CFP of assessment sub-process $n$ of one function unit $(0.28 \mathrm{~kg}), E_{i n}$ is the consumption of energy or fuel $i$ in assessment sub-process $n, \omega_{i}^{d r}$ is the direct CFP conversion factors for energy or fuel $i, \omega_{i}^{i n}$ is the indirect CFP conversion factors for energy or fuel $i, M_{i n}$ is the amount of material input $i$ within assessment sub-process $n, \xi_{i}^{\text {dr }}$ is the direct CFP conversion factors for material $i, \xi_{i}^{i n}$ is the indirect CFP conversion factors for material $i$, and $C h_{i}$ is the GHGs directly emitted by biochemical reaction $i$ in assessment sub-process $n, M_{n}^{\text {loss }}$ is the actual quality loss of the assessment sub-process n. E.g. the product CFP of Dying sub-process of industrial production of pure cotton fabric dyed in dark color, whose basic data are shown in Table A1 (where the basic unit of quantity is $1 \mathrm{~kg}$ so we need do the conversion to the quality of function unit by multiplying $0.28 \mathrm{~kg}$ ) and relevant energy conversion factors for energy resources are shown in Table 5. The energy used in this sub-process are electricity and steam which would not have direct GHGs emission in actual industrial process, that is, the CFP of this sub-process is indirect CFP. The actual CFP of this sub-process of one function unit is calculated as follow.

$$
\begin{aligned}
\text { CFP }_{\text {Dyingsubprocess }}=[ & \left(0.1 \mathrm{kWh} / \mathrm{kg} * 1.383 \mathrm{kgCO}_{2} \mathrm{e} / \mathrm{kWh}\right. \\
& \left.+3.08 \mathrm{~kg} / \mathrm{kg} * 0.054 \mathrm{kgCO}_{2} \mathrm{e} / \mathrm{kg}\right) \\
& \times /(1-5.5 \%)] * 0.28 \mathrm{~kg} \\
= & 0.09 \mathrm{kgCO}_{2} \mathrm{e}
\end{aligned}
$$

\subsection{CFP assessment of every life cycle process and system boundary}

\subsubsection{Cotton production}

The CFP of cotton production includes GHGs from cotton growth and those emitted by cultivation management (Fig. 2). GHGs from cotton growth are the $\mathrm{CO}_{2}$ emitted by plants respiration, which offsets the part absorbed by photosynthesis. The GHGs emitted during cultivation management consist of two parts: direct emission by the use of fertilizer and pesticide, energy consumption, and the disposal of straw such as by burning (Gao et al., 2002); and indirect emission embedded within the use of agricultural machinery and energy consumption during pre-plowing, seeding, irrigation, harvest, and so on.

The present study includes five major cotton production areas, which account for $80 \%$ of the cotton produced in China: Xinjiang, Shandong, Hebei, Henan, and Hubei. The yield and planting proportion for each region is shown in Table 1. The average CFP of cotton in China represents the cotton CFP of each province, weighted according to planting proportion, and divided by the sum of the planting proportions of these five areas.

\subsubsection{Transport of cotton}

The transportation of cottons refers to the transportation from cotton production areas to textile production facilities. According to the production characteristics for cotton and shirts within China, this mainly occurs via freight train. In China, there are three

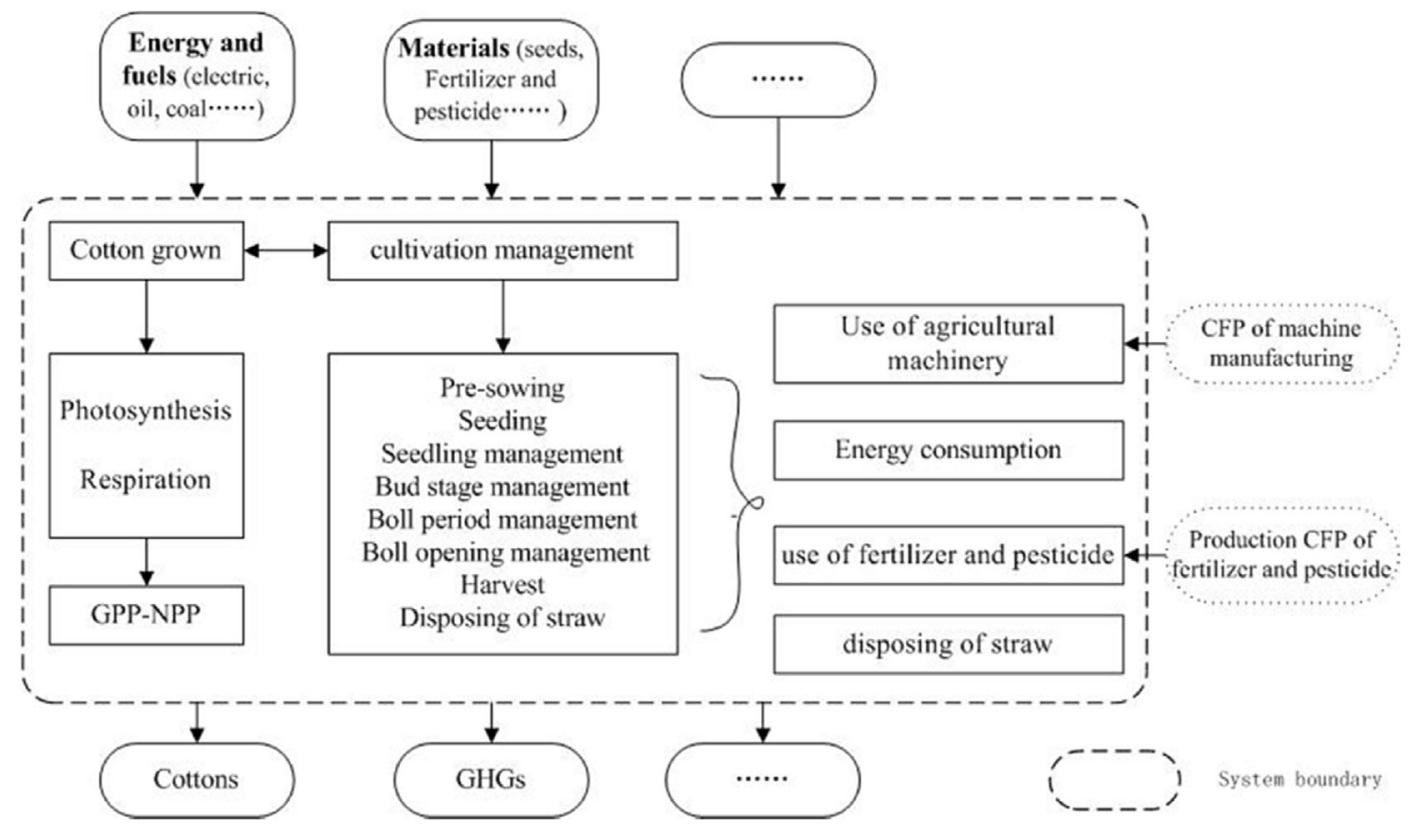

Fig. 2. System boundary for CFP assessment of raw material process. 
Table 1

Yield and planting proportion of five major cotton production areas.

\begin{tabular}{lcc}
\hline Province & Yield, $10^{4} \mathrm{t}$ & Planting proportion, \% \\
\hline Xinjiang & 252.4 & $39.58 \%$ \\
Shandong & 92.1 & $14.45 \%$ \\
Hebei & 60.5 & $9.48 \%$ \\
Henan & 51.7 & $8.11 \%$ \\
Hubei & 48.1 & $7.54 \%$ \\
\hline
\end{tabular}

provinces, Zhejiang, Hunan, and Jiangsu, account for approximately $70 \%$ of shirt production. The transportation distance is estimated by the distance between the provincial capitals of cotton production and textile-producing provinces (Table 2).

Eq. (2) shows the CFP assessment model for transportation:

$$
\begin{aligned}
C F_{\text {trm }} & =S \cdot\left(\sum_{i} E_{i} \cdot \omega_{i}^{d r}+\sum_{i} E_{i} \cdot \omega_{i}^{\text {in }}\right) / M+C_{\text {Loss }} \\
& =S \cdot\left(\omega_{j}^{d r}+\omega_{j}^{\text {in }}\right) / M+C_{\text {Loss }}
\end{aligned}
$$

Here, $C F_{\text {trm }}$ is the CFP were the transportation of cottons, $S$ is the distance between cotton production areas and textile industries, $E_{i}$ is the energy consumption or fuel $i$ per unit distance, $\omega_{i}^{d r}$ is the direct CFP conversion factors of energy or fuel $i, \omega_{i}^{i n}$ is the indirect CFP conversion factors of energy or fuel $i, M$ is the total mass of this transportation of cotton, $C_{\text {Loss }}$ is the direct effusion of GHGs in the transportation process, $\omega_{j}^{d r}$ is the direct CFP of transportation vehicle $j$ in per kilometer where $j$ means airplane, train, or truck, and $\omega_{j}^{i n}$ is the indirect CFP of transportation vehicle $j$ in per kilometer. E.g. in this case study, we estimate the CFP of cotton transportation process by assuming the main transportation vehicle is train which have about average 60 tons load capacity of cotton. The distance data from Xinjiang to Zhejiang is shown in Table 2 and the relevant transportation CFP of cotton with one function unit is shown as follow.

$$
\begin{aligned}
C F P_{\text {transXJtoZhJ }}= & \left(4071 \mathrm{~km} * 0.0989\left(\mathrm{gCO}_{2} \mathrm{e} \mathrm{km}\right)\right. \\
& \times / 60 \mathrm{t} / 50 / 1000 \mathrm{~kg}) * 0.28 \mathrm{~kg} \\
= & 0.036 \mathrm{gCO}_{2} \mathrm{e}
\end{aligned}
$$

\subsubsection{Textile-producing}

The CFP of industrial production is the sum of production CFP, management average CFP, and CFP from other parts. For the production CFP, there are three main sub-processes within the textile industrial producing of the pure cotton shirt: spinning, weaving, and the processing of the textile into clothing; and all of the inputs and outputs within each of the small processes are considered in the production CFP assessment. The management average CFP is those from public management department, such as factory management, business trip, and laboratory and so on, which is not directly related to production. The CFP from other parts mainly includes two aspects. One is those from production supporting system which is directly related to the production activities but not in the production chain, such as transportation in factory areas including forklifts and automobiles; air conditioners, lights, and air compressors in factory plants. The other is from depreciation of factory plants, machines, and fixed installations. The management average CFP and the CFP from other parts are calculated by allocating the GHGs based on the production quantities, which are emitted by the sum of energy and materials consumption of public management department or other parts. The complete system boundary of industrial production is shown in Fig. 3.

Based on the supply and processing chains for shirt production, we investigated several clothing manufacturers to collect data for each process within the industrial production phase: spinning, weaving, and final clothing. That is, we simulate the actual sequence used to produce shirts in order to assess industrial CFP. This framework, representing the production of pure cotton shirts, could be seen as a comprehensive simulation of the main production processes within typical large-scale production facilities in China. In recognition of the difficulty of collecting commercially sensitive data, we selected several typical textiles companies in Guangdong and Shandong with which we have established a good working relationship. The data collected from these companies is representative of the overall scale of Chinese industrial production for each sub-process.

\subsubsection{Transportation of shirts}

The main use of resources in transporting the textiles is the energy consumed by all vehicles. Textile transportation refers to the transportation from textile industries to the domestic or overseas sales territory. According to our investigation, the main transportation vehicles for the textiles are ships, planes, trains, and trucks. We also find that China, USA, and the European Union (EU) are the major sales territories for Chinese pure cotton shirts. The calculation of internal transportation CFP is same as that for cotton transportation discussed in Section 2.4.2. The CFP of exported shirts is calculated for two transportation modes: plane, estimated by the distance from China to the export destination; and ship, estimated by the journey duration. The market share, journey distance, and sailing time to each export destination are shown in Table 3.

We do not calculate the GHG emissions as the CFP of sales, because of the small GHG emissions associated with sales but large differences in sales mode. When assessing the CFP associated with the transportation of textiles for export, we not only calculate the GHG emissions from China to the export countries or regions, but also estimate the transportation within them.

\subsubsection{Product usage}

Washing and drying are the main sources of CFP during use of the product, so the service life of a pure cotton shirt and the washing styles are always the two main impact factors for CFP during the use phase of the product life cycle. We did a sampling investigation to the main consumers of these Chinese pure cotton shirts, and estimated CFP by average washing and drying times and

\begin{tabular}{|c|c|c|c|c|c|c|}
\hline $\mathrm{Km}$ & Cotton production areas & Xinjiang & Shandong & Hebei & Henan & Hubei \\
\hline Textile-producing provinces & Provincial capital & Urumchi & Jinan & Shijiazhuang & Zhengzhou & Wuhan \\
\hline Zhejiang & Hangzhou & 4071 & 1168 & 1389 & 1085 & 866 \\
\hline Hunan & Changsha & 3948 & 1279 & 1314 & 902 & 410 \\
\hline Jiangsu & Nanjing & 3783 & 667 & 965 & 721 & 705 \\
\hline
\end{tabular}
the machines' energy consumption characteristics in different investigated regions.

Table 2

Transportation distance between cotton production and textile-producing provinces. 


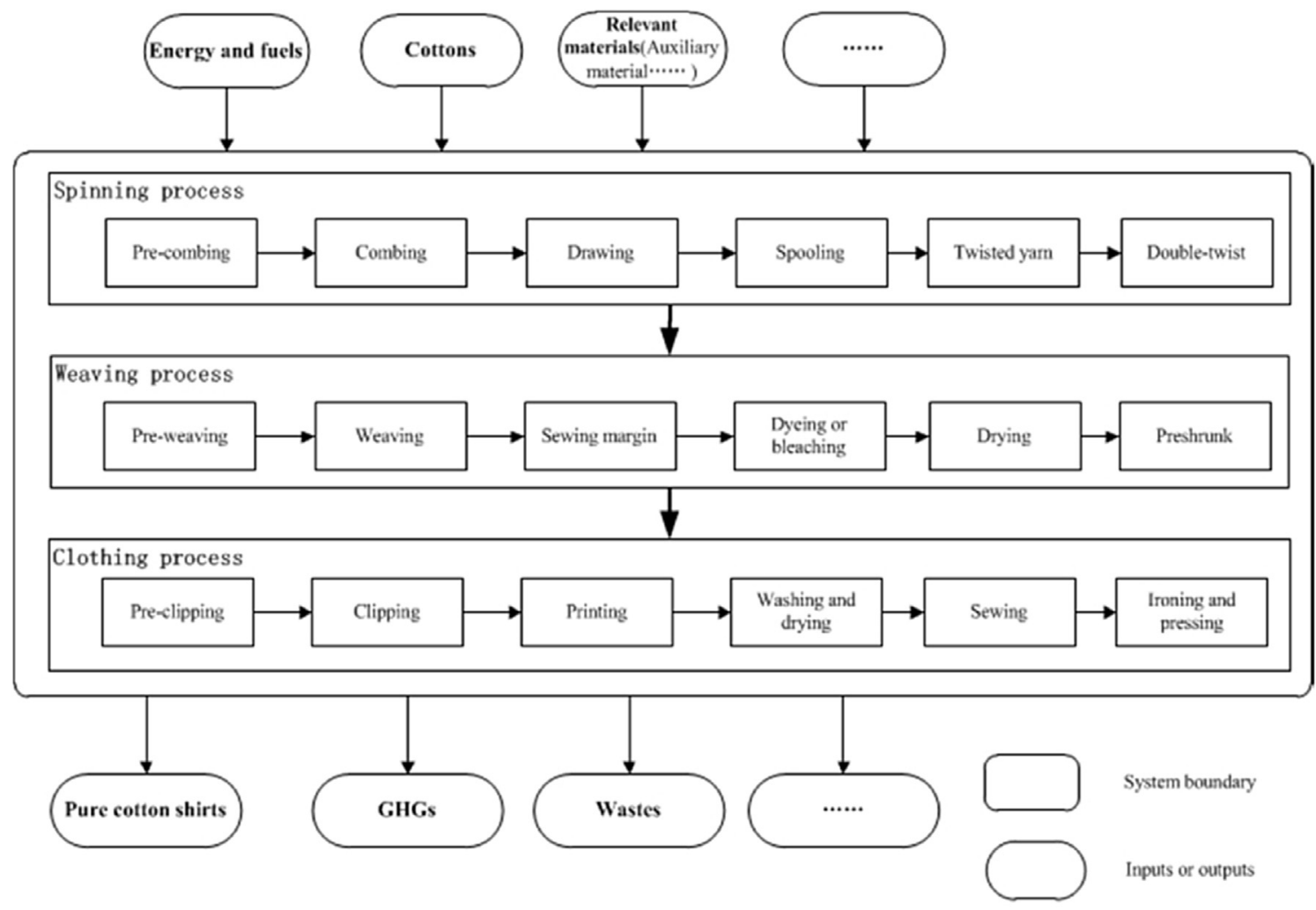

Fig. 3. System boundary of the industrial production process for CFP assessment.

Table 3

Market share, distance, and sailing time to each export destination.

\begin{tabular}{|c|c|c|c|c|}
\hline & & \multirow[t]{2}{*}{ Export proportion } & \multirow{2}{*}{$\frac{\text { By plane }}{\text { Average distance }}$} & \multirow{2}{*}{$\frac{\text { By ship }}{\text { Average sailing time }}$} \\
\hline & & & & \\
\hline Units & & & $(\mathrm{km})$ & (days) \\
\hline \multirow[t]{6}{*}{ Asia } & Hong Kong & $5.71 \%$ & 2289 & 3 \\
\hline & Macao & $0.17 \%$ & 2200 & 3 \\
\hline & Taiwan & $0.48 \%$ & 2500 & 3 \\
\hline & Japan & $14.90 \%$ & 2547 & 3 \\
\hline & Korea & $2.29 \%$ & 1072 & 3 \\
\hline & Turkey & $0.36 \%$ & 7500 & 22 \\
\hline European Union & & $28.17 \%$ & 8503 & 36 \\
\hline Africa & & $3.30 \%$ & 7540 & 35 \\
\hline Australia & & $2.30 \%$ & 8556 & 21 \\
\hline \multirow[t]{3}{*}{ America } & USA & $20.36 \%$ & 11,472 & 28 \\
\hline & Canada & $2.31 \%$ & 8620 & 25 \\
\hline & Mexico & $0.23 \%$ & 12,500 & 25 \\
\hline
\end{tabular}

\subsection{Data collection}

Three types of data sources are used in this research: investigation and survey data, statistical yearbook, and experimental simulation (Table 4). The investigation and survey data were collected in 2009-2010 and mainly relate to production. Data for the industrial production processes tracked the production chains and recorded the statistical data in some typical textile companies, which are representative of the production and operations management within large-scale textile enterprises in China.

\subsection{CFP conversion factors for energy sources in China}

The energy sources involved in this CFP assessment are oil, coal, natural gas, steam, and electricity; oil includes aircraft fuel, gasoline, diesel, kerosene, and lubricating oil. The CFP conversion factors include the GHG emissions associated with the mining, transforming, and transportation processes within the life cycle of the energy sources themselves and the direct GHG emissions from processes like fuel combustion. The direct CFP conversion factors are calculated through the IPCC Guidelines for National Greenhouse Gas Inventories and the China Energy Statistical Yearbook. The indirect conversion factors were estimated based on the previous studies and the Statistical Yearbook, in addition to some chemical experiments in the production chain (Dong et al., 2003; Ma et al., 1999; Wang, 2012; Xia et al., 2010). The assessment processes for the conversion factors are shown in Table A1. Moreover, all of the energy CFP conversion factors are shown in Table 5.

\section{Results}

The average CFP of a pure cotton shirt in life cycle is $8.771 \mathrm{kgCO}_{2} \mathrm{e}$ (Table 6). In descending order, the CFP for each of the processes was estimated as: $4.988 \mathrm{kgCO}_{2} \mathrm{e}$ for the industrial 
Table 4

Data collection for each process in the life cycle.

\begin{tabular}{|c|c|c|c|}
\hline \multirow[t]{2}{*}{ Life cycle process } & \multicolumn{3}{|l|}{ Data sources } \\
\hline & Investigation and survey & Statistical yearbook & Experimental simulation \\
\hline \multicolumn{4}{|l|}{ Cotton-production process } \\
\hline Cotton growth & & & $\sqrt{ }$ \\
\hline Cultivation management & & $\sqrt{ }$ & \\
\hline \multicolumn{4}{|l|}{ Industrial production } \\
\hline Spinning & $\sqrt{ }$ & & \\
\hline Weaving & $\sqrt{ }$ & & \\
\hline Dyeing and finishing & $\sqrt{ }$ & & \\
\hline Clothing & $\sqrt{ }$ & & \\
\hline \multicolumn{4}{|l|}{ Transportation } \\
\hline Transport of raw material & $\sqrt{ }$ & $\sqrt{ }$ & \\
\hline Transportation of textiles & $\sqrt{ }$ & $\sqrt{ }$ & \\
\hline Product usage & $\sqrt{ }$ & & $\sqrt{ }$ \\
\hline
\end{tabular}

Table 5

CFP conversion factors for energy and fuels in China.

\begin{tabular}{|c|c|c|c|c|}
\hline Energy & Unit & Direct & Indirect & CF conversion factors for energy \\
\hline Aviation gasoline & $\mathrm{kgCO}_{2} \mathrm{e} / \mathrm{MJ}$ & 0.070 & 0.756 & 0.827 \\
\hline Gasoline & $\mathrm{kgCO}_{2} \mathrm{e} / \mathrm{kg}$ & 3.114 & 154.369 & 157.484 \\
\hline Diesel oil & $\mathrm{kgCO}_{2} \mathrm{e} / \mathrm{kg}$ & 3.214 & 138.537 & 141.75 \\
\hline Kerosene & $\mathrm{kgCO}_{2} \mathrm{e} / \mathrm{kg}$ & 3.214 & 15.833 & 19.047 \\
\hline Fuel oil & $\mathrm{kgCO}_{2} \mathrm{e} / \mathrm{kg}$ & 3.247 & 31.666 & 34.913 \\
\hline Lubricating oil & $\mathrm{kgCO}_{2} \mathrm{e} / \mathrm{kg}$ & & 7.916 & 7.916 \\
\hline Standard coal & $\mathrm{kgCO}_{2} \mathrm{e} / \mathrm{kg}$ & 0.590 & 0.001 & 0.591 \\
\hline Natural gas & $\mathrm{kgCO}_{2} \mathrm{e} / \mathrm{m}^{3}$ & 2.186 & 2.360 & 4.546 \\
\hline Steam & $\mathrm{kgCO}_{2} \mathrm{e} / \mathrm{kg}$ & & 0.054 & 0.054 \\
\hline Electricity & $\mathrm{kgCO}_{2} \mathrm{e} / \mathrm{kw} \cdot \mathrm{h}$ & 1.015 & 0.360 & 1.383 \\
\hline
\end{tabular}

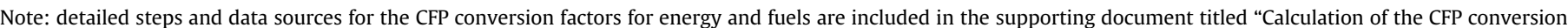
factors for energy resources."

Table 6

Average CFP of a pure cotton shirt and specific results $\left(\mathrm{kgCO}_{2} \mathrm{e}\right)$.

\begin{tabular}{|c|c|c|c|c|c|c|}
\hline \multirow{2}{*}{$\begin{array}{l}\text { Unit: } \mathrm{kgCO}_{2} \mathrm{e} \\
\text { Cotton }\end{array}$} & \multirow{2}{*}{$\frac{\text { Average }}{3.183}$} & \multicolumn{5}{|c|}{ Detailed results } \\
\hline & & \multicolumn{5}{|c|}{ Cotton-production areas } \\
\hline & & Xinjiang & Shandong & Hebei & Henan & Hubei \\
\hline & & 1.461 & 5.170 & 16.203 & 2.235 & 1.860 \\
\hline \multirow[t]{3}{*}{ Transportation of cotton } & 0.003 & Producer & & & & \\
\hline & & Zhejiang & Hunan & Jiangsu & & \\
\hline & & 0.003 & 0.003 & 0.002 & & \\
\hline \multirow[t]{3}{*}{ Industrial production } & 4.988 & Colors & & & & \\
\hline & & White & Pale blue & Rose pink & Black & \\
\hline & & 5.474 & 4.932 & 5.037 & 4.511 & \\
\hline \multirow[t]{3}{*}{ Transportation of textiles } & 0.227 & Sales regi & & & & \\
\hline & & China & USA & EN & else & \\
\hline & & 0.003 & 0.336 & 0.375 & 0.194 & \\
\hline \multirow[t]{3}{*}{ Product use phase } & 0.369 & Use regio & & & & \\
\hline & & China & USA & EN & & \\
\hline & & 0.295 & 0.444 & 0.369 & & \\
\hline Total & 8.771 & & & & & \\
\hline
\end{tabular}

production process, $3.183 \mathrm{kgCO}_{2} \mathrm{e}$ for raw materials, $0.227 \mathrm{kgCO}_{2} \mathrm{e}$ for transportation associated with production, $0.977 \mathrm{kgCO}_{2} \mathrm{e}$ for the use phase of the product life cycle, and $2.782 \mathrm{gCO}_{2} \mathrm{e}$ for the transportation of cottons.

The CFP contribution analysis of each life cycle process is shown in Fig. 4. The production process (including raw material and industrial production) contributes $93.16 \%$ of the average CFP. Within industrial production, each sub-process contributes the following: weaving (34.45\%), spinning (19.8\%), and processing into clothing (2.62\%).
Approximately 96\% of the CFP consists of indirect factors, such as the use of energy and materials embedded in every process (Fig. 4). The highest indirect CFP is that for raw materials (4.249 $\mathrm{kgCO}_{2} \mathrm{e}$ ), followed by that for industrial production (3.806 $\left.\mathrm{kgCO}_{2} \mathrm{e}\right)$. Within the production and weaving processes, transportation accounts for nearly all of direct CFP, which is $0.347 \mathrm{kgCO}_{2} \mathrm{e}$ in total, and it is worth considering that, because of the photosynthesis of cotton during its growth period, the direct CFP for raw materials is negative. 


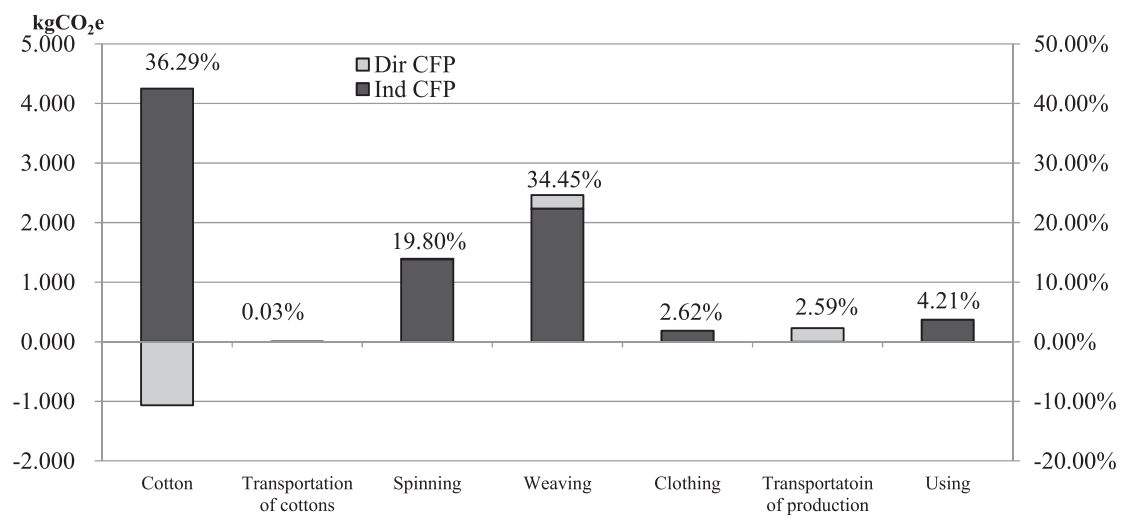

Fig. 4. Contribution and composition of each process to CFP.

\section{Discussion}

\subsection{Uncertainty and sources of error}

The sources of uncertainty in this study mainly relate to the realism of the CFP assessment method and potential data errors (Lloyd and Ries, 2007). The reliability of the method mainly depends on the completeness of the assessment framework and the system boundary. The framework presented here references not only the existing methodologies of the ISO, Carbon Trust, IPCC, and others but, as far as possible, includes all of the main processes involved in the life cycle of the product. The present assessment method therefore has relatively high certainty.

All of the data sources, including statistical yearbooks, investigation and survey, and experimental simulation, have the potential to introduce errors. The statistical yearbooks data are official data that it is not possible to judge the reliability of this data and such yearbooks are relied upon for a wide range of studies. The investigation and survey data were collected by recording the actual readouts from production equipment, or were calculated from the specification data sheet. The data were further verified by comparing the sum of every sub-process with statistical data for overall consumption of materials energy sources within the companies, in order to ensure that any errors in the data did not have an obvious effect on the final results. In the assessment of transportation and using CFP, we used data from small-scale experimental simulations, which were estimated by scenario planning based on real cases; as a result, these are likely to have lower accuracy than the investigation and survey data and the statistical data. However, the experimental simulation data are not the

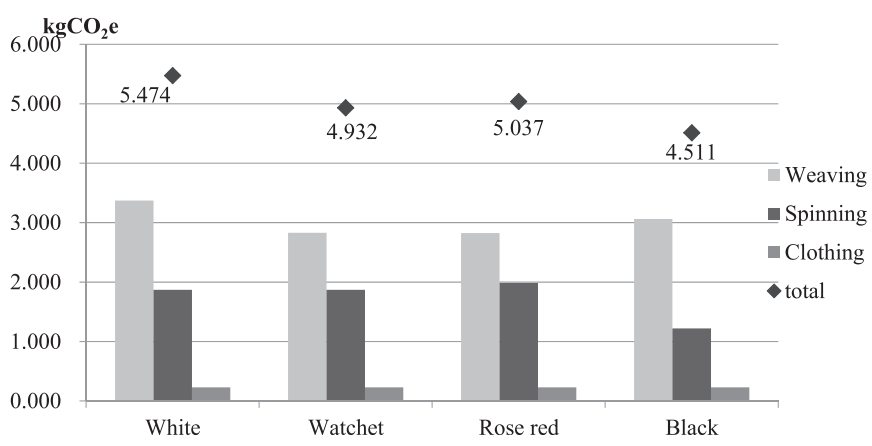

Fig. 5. CFP of shirt within the industrial production process. preferred data mode, and are only to ensure the completeness of the calculations and results, when it was not possible to acquire the investigation and survey data. Analyzing the final CFP results, the transportation and usage phases both represent relatively small proportions of the final results, and therefore any error within these two phases would not have a substantial influence on the overall findings. Rather, the CFP methodology indicates which factors would influence the CFP of a product, thereby enabling consumers to make contributions to reducing GHG emissions through more sustainable lifestyle changes and purchasing decisions. We did not pursue precise calculations during the usage phase, because consumption habits vary between individuals; the study therefore represents a simple, abstract example, providing general analysis and conclusions on regional modes of consumption.

\subsection{Analysis of individual life-cycle process}

\subsubsection{Cotton}

The CFP of cotton varies greatly between different cultivation regions. The CFP of cotton was largest in the Hebei province, followed by Shandong, Henan, and Hubei; it was smallest in the Xinjiang province. According to the statistical and investigative data, Xinjiang province has the largest cotton cultivation areas and the highest production, but the use of chemical fertilizer, pesticide, and energy inputs is far lower than other provinces, which results in the lowest GHG emissions.

\subsubsection{Production}

The CFPs of the industrial production processes arranged in descending order are weaving, spinning, and clothing. Indirect CFPs accounted for more than $90 \%$ of the industrial production CFP, because energy consumption for steam and electricity were the main contributors to the CFP in the manufacturing stage (Fig. 5).

Unlike our general assumption, color was not an important influencing factor of the industrial production CFP. This is because the dyeing process was heavily dependent on water but not on energy. Our research on the water footprint of shirts showed that the choice of textile color had a substantial impact on water footprint (Yan et al., 2014). Shirts manufactured in different colors show substantial differences in water consumption in the dying or washing process, but little differences in the energy consumption. The obvious difference between CFP and water footprint also shows that variations of a single product can have differing impacts on the range of environmental elements (Jia et al., 2012). The findings emphasize the importance of considering the complex influences 
on several environmental assessment criteria when developing environmental impact policies making or management decisions.

\subsubsection{Transportation}

(1) The average CFP of cotton transportation is $3 \mathrm{gCO}_{2} \mathrm{e}$. The CFP differs for the specific transportation conditions, between the various cotton production and shirt-producing provinces. For example, the average CFP of cotton transportation from Xinjiang province is $7 \mathrm{gCO}_{2} \mathrm{e}$, where the average distances to the three major production centers is $4000 \mathrm{~km}$. The results show that the geographical distribution of the cotton cultivation and textiles sectors is the primary influence on transportation CFP. However, there are many factors influencing the industrial distribution.

(2) The average CFP of textile transportation for export is $0.194 \mathrm{kgCO}_{2} \mathrm{e}$, which is much higher than that for domestic sales (approximately $0.003 \mathrm{kgCO}_{2} \mathrm{e}$ ).

(3) The average CFP conversion factors for each transportation mode, in descending order, are: plane, truck, ship, and train. Within the transportation process, the transportation modes and distance are the main factors determining the textile transportation CFP.

\subsubsection{Usage}

The CFP assessment for the usage phase only reflects the general differences in consumption between each region and their influences on the footprint. Based on the small survey of personal lifestyles in China, the USA, and the EU, we find that about $50 \%$ of people in China use a washing machine, whereas few use a clothes dryer (Huang et al., 2013); almost all American households use both washing machines and dryers; in Europe, the results differ between countries. In a washing and drying cycle, the water temperature and cycle duration are the main factors that determine the CFP of the usage phase. Bevilacqua et al. (2011) found that higher water temperature resulted in larger CFP, where the average CFP of using water at a temperature of $30{ }^{\circ} \mathrm{C}$ was more than three times that when using cold water.

\subsection{Average CFP of a shirt}

The average CFP of a shirt is based on the investigation and observation of the life cycle. The overall CFP reflects the basic GHG emissions associated with each process under assumption. For each process; the average CFP for cotton is weighted by the planting proportion of cottons in China, which could represent the general condition of cotton planting. The CFP of industrial production could show the general production degree of the investigated companies; however, because of the diversity of Chinese textiles enterprises in scale, technology, and consumption of energy sources and materials, it could not completely represent the average level for all Chinese shirts, even from family working. The CFP of transportation could be used to reflect the basic influence of regional differences, but could not be applied to the comparison of a specific transit route. The CFP for the usage phase shows some macro-regional difference, but it does not mean that the personal activities within these regions are same.

At present, many studies of textile CFP focus on the production process. For example, our results for industrial production CFP are approximately one-third of that estimated for a pure white cotton shirt (1.8 $\mathrm{kgCO}_{2} \mathrm{e}$ per piece) in a study by the Carbon Trust (Specification, 2011). The main causes of this discrepancy are the differing data accuracy and system boundaries used in the assessments. In the present study, the system boundary includes the most complete assessment possible of every input and output for every sub-process involved in the industrial production of shirts, and the data were obtained by tracking and measuring every sub-process and machine. However, we do not have more specific information from the study by the Carbon Trust in order to understand and compare the accuracy of the data sources and to understand the principles used to construct the system boundary, which would be necessary even to reflect the essential difference between these two countries in the CFP of textiles. Furthermore, the requirements for details and realistic process modeling in our assessment perhaps caused greater error accumulation.

Another comparison could be made with woolen sweaters. In the raw material process, according to Ripoll-Bosch in Australia, the average CFP of wool production is about $24.9 \mathrm{kgCO}_{2} \mathrm{e} / \mathrm{kg}$ (Brock et al., 2013; Henry, 2012; Ripoll-Bosch et al., 2013), which the CFP of cotton is much lower that it. Assuming that there is little difference between the industrial production and other processes, the pure cotton shirts may have a lower CFP than the woolen sweaters. Because of the substantial differences in system boundary and data accuracy, it is not possible to compare the present study with the supply chain for a woolen sweater (Bevilacqua et al., 2011). Based on the present findings for raw material process, consumers should be encouraged to choose cotton shirts rather than woolen sweaters.

\section{Conclusions}

This paper has constructed a comparable CFP assessment system and framework that contains almost all the main processes in the life cycle of a shirt. The assessment method from bottom to top, based on the life cycle methodology, has offered the specific calculation to an integrated assessment of the CFP of shirts. The methods in this research are also appropriate to the production of many other textiles in China. Additionally, the conversation factors estimated in this paper have been appropriate to the assessment of other products.

The results showed that the average CFP of a pure cotton shirt produced in China, throughout its life cycle, was $8.771 \mathrm{kgCO}_{2} \mathrm{e}$, of which the indirect CFP of $8.423 \mathrm{kgCO}_{2} \mathrm{e}$ is much higher than the direct CFP of $0.347 \mathrm{kgCO}_{2} \mathrm{e}$. Within the textile life cycle, the industrial production stage have represented the largest proportion of CFP; the sub-process of industrial production have been categorized as weaving, spinning, and clothing; and indirect CFP comprises the main component of the industrial production CFP. The production stage (including agriculture and industrial production) have accounted for more than $90 \%$ of the total CFP.

Based on the investigation of industrial production and scenario planning of some processes in the life cycle, the assessment process and results in this paper could reasonably reflect the average CFP values for large-scale production of shirts in China. The results could partially represent the present situation for carbon emissions within the Chinese textiles sector; and could also support processes to manage the carbon footprint in the related companies, and provide some basic data to guide more sustainable patterns of consumption. However, it must be pointed out that the CFP estimated in this research does not imply a specific carbon responsibility for China. More significant to this paper is that the assessment system and framework in this work provide a more focused approach to the assessment of textiles or other products in China.

The bottom-up assessment methodology in this study based on direct data from detailed process in life cycle has clarifying the specific system boundary. Result of CFP by such methodology can 
be disassembled and reassembled, which make it possible to compare the results from different assessments of similar products. Contrastively, the CFP assessment result by the top-down methodology is mainly based on the allocation of gross data, which is difficult to compare among different assessments due to the difference of system boundary and difficulty to disassemble and reassemble. The obstacle of the bottom-up assessment methodology is difficulty in data collection, that's why there are few CFP assessment cases by such methodology till now. Another difficulty in application of this methodology is its high requirement on data accuracy, because the result error would be unacceptable and even exceed that by top-down methodology due to error accumulation of inaccurate data. Likewise, we had difficulties in data collection in this study, and had to treat some data by estimation and allocation, especially in data of equipment or process without individual metering. Therefore, we testified those data by upper level direct metering data in every data collecting process to ensure the reliability of result.

As one of the important mechanisms for controlling and managing emissions of GHGs, comparisons between different fungible products and between the same products from different producers could help to reduce production CFP across the whole of society. Future assessments of fungible products, for example comparisons of T-shirts or shirts containing cotton or wool, should be conducted using a consistent framework and reporting methodology in order to encourage consumers to select those associated with lowercarbon production. Comparison of the same products from different producers requires higher-resolution methods, frameworks, and data. In terms of the actual CFP assessment, producers have insufficient experience of measuring and collecting basic data, and the available data also lack sufficient accuracy to support comparisons between different producers. Further work to reinforce basic data measurement and the assessment of CFP in each process of a product life cycle would expand the application of production CFP assessment and provide databases for the routine application of CFP toward the management and reduction of GHG emissions.

\section{Acknowledgments}

This study was supported by the National Key Technologies R\&D Program (No. 2013BAJ04B01) and State Key Laboratory of Urban and Regional Ecology (SKLURE 2013-1-02) of China. The confidentiality agreement with the participating textile companies means we are unable to directly express our gratitude for their substantial assistance in the investigation and data collection. Nevertheless, we would like to thank Mr. Wu, Ms Liu, Ms Wang, and colleagues for their help.

\section{Appendices}

Table A1

Assessment process of conversion factors for energy resources.

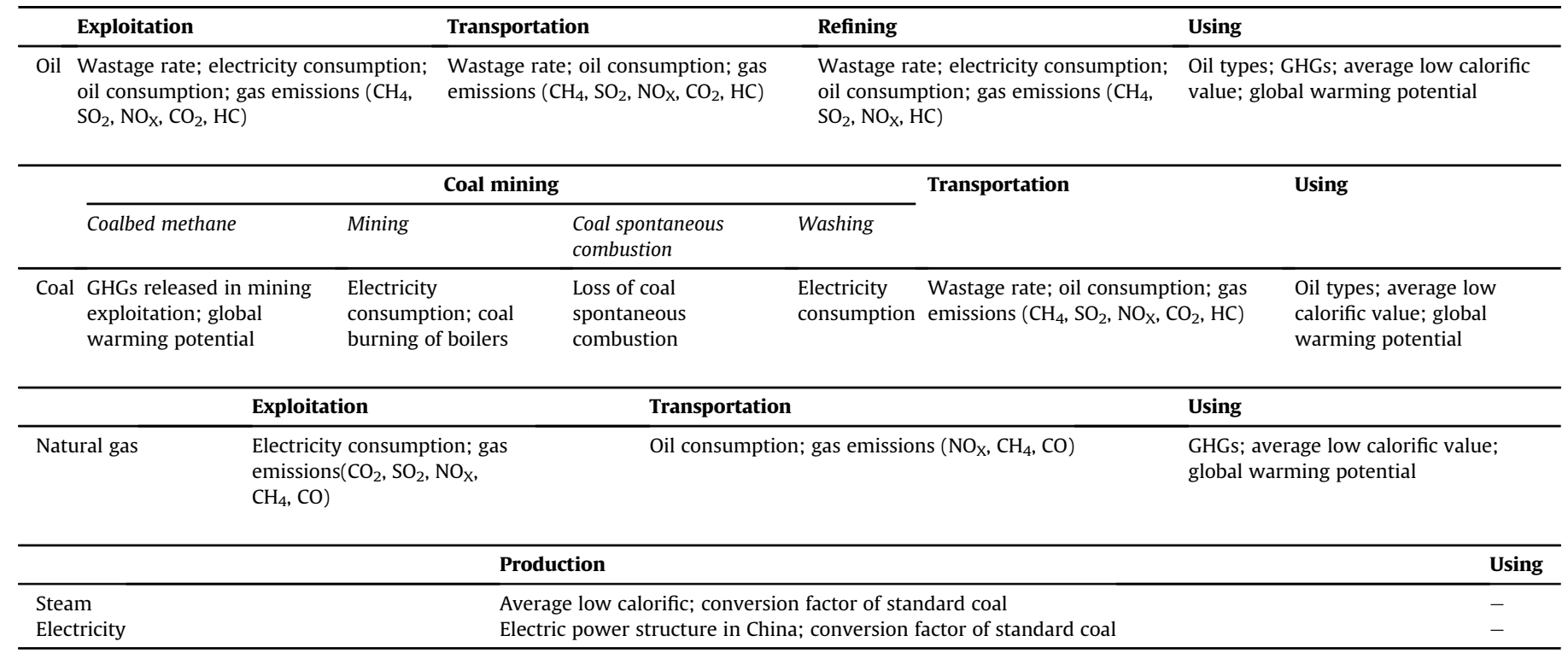

Table A2

Electricity consumption for cotton yarns in spinning sub-process of industrial production during the investigation period (Mar. 2010).

\begin{tabular}{|c|c|c|c|c|c|c|}
\hline \multirow[t]{2}{*}{ Types } & \multicolumn{6}{|c|}{ Electricity consumption of cotton yarn } \\
\hline & Blowing & Cotton carding & Combing & Drawing and roving process & Spinning yarn & Spooling \\
\hline JC28.1s & 84,816 & 84,816 & 49,104 & 124,992 & 357,120 & 133,920 \\
\hline $\mathrm{JC} 18.5 \mathrm{~s}$ & 84,816 & 84,816 & 89,280 & 93,744 & 357,120 & 133,920 \\
\hline $\mathrm{JC} 14.8 \mathrm{~s}$ & 42,408 & 42,408 & 44,640 & 62,496 & 357,120 & 133,920 \\
\hline JC9.8s & 42,408 & 42,408 & 44,640 & 62,496 & 714,240 & 267,840 \\
\hline
\end{tabular}

Notes: due to the limitations imposed by a confidentiality agreement with the participating textiles companies, the management data cannot be shown. 
Table A3

Data for cotton fabrics in weaving sub-process of industrial production.

\begin{tabular}{|c|c|c|c|c|c|c|c|c|c|}
\hline \multirow[t]{3}{*}{ Process } & \multicolumn{4}{|c|}{ Bleached fabric with plain weave process } & \multirow[t]{3}{*}{ Process } & \multicolumn{4}{|c|}{ Dyed pure cotton fabric in light color } \\
\hline & \multirow[t]{2}{*}{ Mass loss \% } & \multirow{2}{*}{$\frac{\text { Electricity }}{\mathrm{kWh} / \mathrm{kg}}$} & \multirow[t]{2}{*}{ Steam kg/kg } & \multirow{2}{*}{$\frac{\text { Coal }}{\mathrm{kg} / \mathrm{kg}}$} & & \multirow[t]{2}{*}{ Mass loss \% } & \multirow{2}{*}{$\frac{\text { Electricity }}{\mathrm{kWh} / \mathrm{kg}}$} & \multirow[t]{2}{*}{ Steam $\mathrm{kg} / \mathrm{kg}$} & Coal \\
\hline & & & & & & & & & $\mathrm{kg} / \mathrm{kg}$ \\
\hline Weaving & 2.2 & 0.068 & & & Weaving & 2.2 & 0.1 & & \\
\hline Examining cloth & 0.1 & 0.001 & & & Examining cloth & 0.1 & 0.001 & & \\
\hline Releasing & 0.12 & 0.002 & & & Releasing & 0.12 & 0.002 & & \\
\hline Margin to seam & & 0 & & & Margin to seam & & 0 & & \\
\hline Bleaching & 5.5 & 0.062 & 1.22 & & Dying & 7.5 & 0.083 & 2.15 & \\
\hline Scutching & & 0.004 & & & Scutching & & 0.004 & & \\
\hline Drying & & 0.125 & 1.23 & & Drying & & 0.125 & 1.23 & \\
\hline $\begin{array}{l}\text { Intermediate } \\
\text { quality control } \\
\text { examination }\end{array}$ & 0.6 & 0.001 & & & $\begin{array}{l}\text { Intermediate quality } \\
\text { control examination }\end{array}$ & 0.6 & 0.001 & & \\
\hline Sizing & 1.5 & 0.107 & & 0.157 & Sizing & 1.5 & 0.107 & & 0.157 \\
\hline Preshrunk & & 0.009 & 0.27 & & Preshrunk & & 0.009 & 0.27 & \\
\hline Examining & 1.1 & 0.009 & & & Examining & 1.1 & 0.009 & & \\
\hline Packaging & & 0.002 & & & Packaging & & 0.002 & & \\
\hline \multirow[t]{3}{*}{ Process } & \multicolumn{4}{|c|}{ Pure cotton fabric dyed medium color } & Process & \multicolumn{4}{|c|}{ Pure cotton fabric dyed dark color } \\
\hline & Mass loss \% & Electricity & Steam kg/kg & Coal & & Mass loss \% & Electricity & Steam kg/kg & Coal \\
\hline & & $\mathrm{kWh} / \mathrm{kg}$ & & $\mathrm{kg} / \mathrm{kg}$ & & & $\mathrm{kWh} / \mathrm{kg}$ & & $\mathrm{kg} / \mathrm{kg}$ \\
\hline Weaving & 2.2 & 0.082 & & & Weaving & 2.2 & 0.148 & & \\
\hline Examining cloth & 0.1 & 0.001 & & & Examining cloth & 0.1 & 0.001 & & \\
\hline Releasing & 0.12 & 0.002 & & & Releasing & 0.12 & 0.002 & & \\
\hline Margin to seam & & 0 & & & Margin to seam & & 0 & & \\
\hline Dying & 5.5 & 0.084 & 2.5 & & Dying & 5.5 & 0.1 & 3.08 & \\
\hline Scutching & & 0.004 & & & Scutching & & 0.004 & & \\
\hline Drying & & 0.125 & 1.23 & & Drying & & 0.125 & 1.23 & \\
\hline $\begin{array}{l}\text { Intermediate } \\
\text { quality control } \\
\text { examination }\end{array}$ & 0.6 & 0.001 & & & $\begin{array}{l}\text { Intermediate quality } \\
\text { control examination }\end{array}$ & 0.6 & 0.001 & & \\
\hline Sizing & 1.5 & 0.107 & & 0.157 & Sizing & 1.5 & 0.107 & & 0.157 \\
\hline Preshrunk & & 0.009 & 0.27 & & Preshrunk & & 0.009 & 0.27 & \\
\hline Examining & 1.1 & 0.009 & & & Examining & 1.1 & 0.009 & & \\
\hline Packaging & & 0.002 & & & Packaging & & 0.002 & & \\
\hline
\end{tabular}

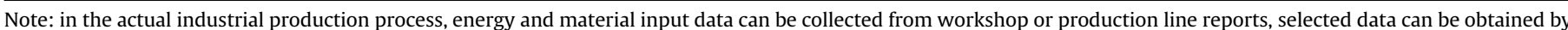

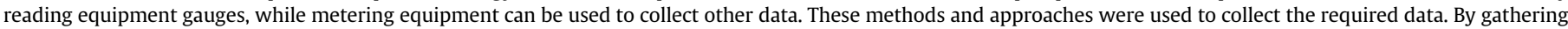

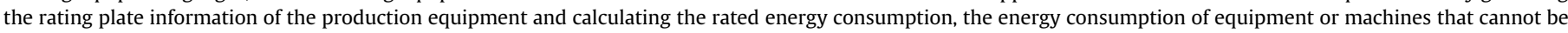

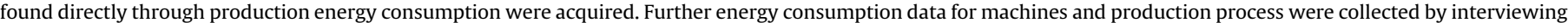
skilled labor employees when the previously described methods were not appropriate.

Table A4

Investigation data of management and other sections in weaving sub-process during the investigation period (2010).

\begin{tabular}{|c|c|c|c|c|}
\hline & Section & Energy & Unit & Dosage \\
\hline \multirow[t]{9}{*}{ Participating producer of cotton fabrics } & Technical section & Electricity & kWh & $2,049,120$ \\
\hline & Storage section & Electricity & $\mathrm{kWh}$ & 521,136 \\
\hline & Engineering function & Electricity & kWh & 195,840 \\
\hline & Waterworks & Electricity & $\mathrm{kWh}$ & $5,267,496$ \\
\hline & Boiler & Electricity & $\mathrm{kWh}$ & $4,105,536$ \\
\hline & & Coal & $\mathrm{t}$ & 35,858 \\
\hline & Living quarters and restaurants & Electricity & kWh & $2,856,792$ \\
\hline & & Steam & $\mathrm{t}$ & 11,784 \\
\hline & Vehicle fuel & Gasoline & $\mathrm{kg}$ & 129,669 \\
\hline
\end{tabular}

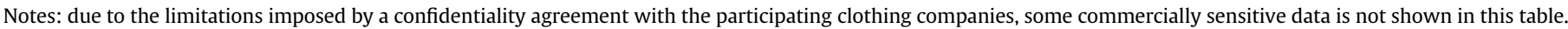

\section{Appendix A. Supplementary data}

Supplementary data related to this article can be found at http:// dx.doi.org/10.1016/j.jclepro.2015.05.127.

\section{References}

Bevilacqua, M., Ciarapica, F.E., Giacchetta, G., Marchetti, B., 2011. A carbon footprint analysis in the textile supply chain. Int. J. Sustain. Eng. 4, 24-36.
Brito de Figueirêdo, M.C., Kroeze, C., Potting, J., da Silva Barros, V., Sousa de Aragão, F.A., Gondim, R.S., de Lima Santos, T., de Boer, I.J.M., 2013. The carbon footprint of exported Brazilian yellow melon. J. Clean. Prod. 47, 404-414.

Brock, P.M., Graham, P., Madden, P., Alcock, D.J., 2013. Greenhouse gas emissions profile for $1 \mathrm{~kg}$ of wool produced in the Yass Region, New South Wales: a life cycle assessment approach. Anim. Prod. Sci. 53, 495.

BSI, Carbon Trust, Defra, 2011. PAS 2050: Specification for the Assessment of the Life Cycle Greenhouse Gas Emissions of Goods and Services.

Change, I.P.o.C., 2006. Guidelines for National Greenhouse Gas Inventories. IPCC, Geneva.

Chen, J.W., Wang, J., 2006. Research on life cycle impact assessment of garment. J. Qingdao Univ. (E\&T) 21, 71-76.

Chen, J.W., Wang, J., 2009. Research on environmental influence of consumer use processes based on LCA. J. Qingdao Univ. (E\&T) 24, 76-79. 
Dai, F.Z., Wu, D., Wang, D.Y., Du, C., Liu, X.L., Yi, S.X., Huang, S.L., Wang, L.H., Yan, Y., 2011. Analysis on assessment and application of carbon footprint of industrial production process. Ecol. Econ. 28-33.

Dias, A.C., Arroja, L., 2012. Comparison of methodologies for estimating the carbon footprint - case study of office paper. J. Clean. Prod. 24, 30-35.

Dong, Z.Q., Ma, X.Q., Zhang, L., Zhao, Z.L., 2003. Life cycle assessment for influence of using nature gas on environment. Nat. Gas. Ind. 23, 126-130.

Dormer, A., Finn, D.P., Ward, P., Cullen, J., 2013. Carbon footprint analysis in plastics manufacturing. J. Clean. Prod. 51, 133-141.

Finnveden, G., Hauschild, M.Z., Ekvall, T., Guinee, J., Heijungs, R., Hellweg, S. Koehler, A., Pennington, D., Suh, S., 2009. Recent developments in life cycle assessment. J. Environ. Manag. 91, 1-21.

Gao, X.Z., Ma, W.Q., Ma, C.B., Zhang, F.S., Wang, Y.H., 2002. Analysis on the current status of utilization of crop straw in China. J. Huazhong Agric. Univ. 21, 242-247.

Heijungs, R., Huppes, G., Guinée, J.B., 2010. Life cycle assessment and sustainability analysis of products, materials and technologies. Toward a scientific framework for sustainability life cycle analysis. Polym. Degrad. Stab. 95, 422-428.

Henry, B., 2012. Understanding the Environmental Impacts of Wool: a Review of Life Cycle Assessment Studies.

Herva, M., Alvarez, A., Roca, E., 2012. Combined application of energy and material flow analysis and ecological footprint for the environmental evaluation of a tailoring factory. J. Hazard. Mater. 237-238, 231-239.

Huang, R., Sun, Q.Zh., Wu, X.Y., Ding, X.M., 2011. Low carbon certification in textile and apparel industry. Print. Dye. 14, 40-44.

Huang, R., Wu, X.Y., Ding, X.M., 2013. Research and the accounting model of carbon emissions in household clothes washing among Shanghai's urban families. Dye. Finish. 11, 36-40.

Jamali-Zghal, N., Amponsah, N.Y., Lacarriere, B., Le Corre, O., Feidt, M., 2013. Carbon footprint and emergy combination for eco-environmental assessment of cleaner heat production. J. Clean. Prod. 47, 446-456.

Jia, J., Yan, Y., Wang, C.X., Liang, Y.J., Zhang, Y.J., Wu, G., Liu, X.L., Wang, L.H., Du, C., 2012. The estimation and application of the water footprint in industrial processes. Acta Ecol. Sin. 32, 6558-6565.

Li, Y., 2009. Theoretical foundation for engineering design of functional textiles. J. Xi'an Polytech. Univ. 23, 1-9.

Lloyd, S.M., Ries, R., 2007. Characterizing, propagating, and analyzing uncertainty in life-cycle assessment: a survey of quantitative approaches. J. Ind. Ecol. 11.
Ma, Z.H., Pan, Z.Q., He, H.M., 1999. Greenhouse gas emission factor for coal power chain in China and the comparison with nuclear power chain. Chin. J. Nucl. Sci. Eng. 19, 268-273.

Muthu, S.S., Li, Y., Hu, J.Y., Ze, L., 2012. Carbon footprint reduction in the textile process chain: recycling of textile materials. Fibers Polym. 13, 1065-1070.

Pennington, D.W., Potting, J., Finnveden, G., Lindeijer, E., Jolliet, O., Rydberg, T., Rebitzer, G., 2004. Life cycle assessment part 2: current impact assessment practice. Environ. Int. 30, 721-739.

Rebitzer, G., Ekvall, T., Frischknecht, R. Hunkeler, D., Norris, G., Rydberg, T. Schmidt, W.P., Suh, S., Weidema, B.P., Pennington, D.W., 2004. Life cycle assessment part 1: framework, goal and scope definition, inventory analysis, and applications. Environ. Int. 30, 701-720.

Ripoll-Bosch, R. de Boer, IJ.M., Bernués, A., Vellinga, TV., 2013. Accounting for multi-functionality of sheep farming in the carbon footprint of lamb: a comparison of three contrasting Mediterranean systems. Agric. Syst. 116, 60-68.

Specification, P.A., 2011. PAS 2050, 2011. Specification for the Assessment of the Life Cycle Greenhouse Gas Emissions of Goods and Services.

Standardization, I.O.f., 2013. ISO 14067 Carbon Footprint of Products-Requirements and Guidelines for Quantification and Communication.

Sun, Q.Z., Wang, L.H., Liu, X.W., Wang, L.L., Wu, X.Y., 2011. Carbon footprint and textile industry. China Text. Lead. 3, 15-18.

Tang, C.Y., Wan, R., 2003. The life cycle inventory on cotton textiles. Shanghai Text. Sci. Technol. 31, 1-4.

Wang, Q.R., 2012. An empirical research on measuring carbon dioxide emissions from urban tourism: a case study of Shenzhou. Geogr. Geo-Inf. Sci. 28, 104-109.

Wang, L.L., Wu, X.Y., Ding, X.M., Wang, L.H., Yu, J.M., 2012. Case study on industria carbon footprint and industrial water footprint of cotton knits. Dye. Finish. 07, 43-46.

Wiedmann, T., Minx, J., 2008. A Definition of 'Carbon Footprint'. Nova Science Publisher, Hauppauge, NY, USA, pp. 1-11.

Xia, D.J., Ren, Y.L., Shi, L.F., 2010. Measurement of life-cycle carbon equivalent emissions of coal-energy chain. Stat. Res. 27, 82-89.

Yan, Y., Jia, J., Wang, L.H., Du, C., Liu, X.L., Fu, X., Liu, X., Wu, G., 2014. The industrial water footprint of several typical cotton textiles in China. Acta Ecol. Sin. 34, $7119-7126$.

Zhao, N.H., Zhou, X., Dong, F., 2012. Carbon footprint assessment of polyester textiles. Dye. Finish. 14, 42-46. 